\title{
Loxoscelismo necrótico palpebral y reconstrucción con autoinjerto cutáneo. Reporte de un caso
}

\section{Eyelid necrotic loxoscelism and reconstruction with cutaneous autograft. A case report}

\author{
Juliana M. Morales-Avalos ${ }^{1 *}$, Adolfo J. Torres-Moreno², Román Zamora-Gómez ${ }^{3}$ e Hiram J. Arce-Sánchez ${ }^{3}$ \\ ${ }^{1}$ Servicio de Oftalmología Oculoplástica; ${ }^{2}$ Servicio de Oftalmología del Segmento Anterior; ${ }^{3}$ Servicio de Infectología. Hospital General de Culiacán,
} Culiacán, Sinaloa, México

\section{Resumen}

En nuestro medio son frecuentes las mordeduras por arañas venenosas debido a que su presencia abarca la mayor parte del país. Las dos especies más comunes son la araña violinista o parda (Loxosceles reclusae) y la araña capulina o viuda negra (Latrodectus mactans). Se consideran venenosas porque provocan una lesión cutánea por la mordedura, seguida de la inoculación de sustancias tóxicas que lesionan los tejidos, condicionando alteraciones fisiopatológicas de gravedad variable. La necrosis es característica de la mordedura por loxosceles, conocida como loxoscelismo. Presentamos el caso de un paciente de 56 años, sin antecedentes patológicos sistémicos, que desarrolló un cuadro inflamatorio que involucró el párpado superior a la región orbitaria extraconal superior. Su evolución a la necrosis requirió debridación de tejidos y reconstrucción con autoinjerto cutáneo de espesor completo del párpado superior contralateral, con una evolución satisfactoria.

Palabras clave: Mordedura de araña venenosa. Loxoscelismo. Loxoscelismo necrótico palpebral. Autoinjerto cutáneo. Reconstrucción palpebral.

\section{Abstract}

Poisonous spider bites are common in our territory due to their presence throughout the country, and the two most common species are the violin or brown recluse spider (Loxosceles reclusae) and the capulin or black widow spider (Latrodectus mactans). They are considered poisonous because they inoculate toxic substances that injure the tissues after a bite, causing pathophysiological alterations of variable severity. Necrosis is characteristic of a loxosceles bite, known as loxoscelism. We present the case of a 56-year-old male with no relevant history. He developed an inflammatory condition that involved the upper eyelid and the superior extraconal orbital region. Its evolution to necrosis required tissue debridation and reconstruction with a full-thickness cutaneous autograft from the contralateral upper eyelid, with a satisfactory evolution.

Key words: Bite of poisonous spider. Loxoscelism. Eyelid necrotic loxoscelism. Skin autograft. Eyelid reconstruction. 


\section{Introducción}

El paciente presentó un cuadro de rápida evolución, desconocía el origen de su padecimiento y solo refirió, en el interrogatorio, haber observado arañas pardas en su domicilio.

Para el presente estudio realizamos una revisión de las mordeduras por Loxosceles reclusae (araña violinista o parda), que se caracterizan por desarrollar vasculitis asociada a necrosis, y son las más comunes en nuestro medio.

Loxesceles son arañas pequeñas, de 9 a $25 \mathrm{~mm}$, en la parte dorsal tienen una mancha oscura de color café en forma de violín invertido, son comunes en la zona noroeste de México y pueden vivir a temperaturas de 8 a $40{ }^{\circ} \mathrm{C}$. Son de hábitos nocturnos y se encuentran en espacios poco transitados, detrás o debajo de objetos de poco uso ${ }^{1,2}$.

El cuadro clínico de la mordedura de la araña violinista o parda (loxoscelismo) se produce por la inoculación de su veneno, que contiene diversas enzimas, de las cuales la esfingomielinasa $D$ es la causante de la necrosis y la hemólisis, pues produce una reacción inflamatoria mediada por el ácido araquidónico y las prostaglandinas que condiciona una vasculitis ${ }^{3-5}$. La expresión clínica puede ser cutánea o sistémica, debido a que la intensidad de la reacción depende de la cantidad de veneno inoculado, así como de la susceptibilidad de la persona a los componentes ${ }^{6,7}$. El cuadro clínico cutáneo es el más frecuente, en un $80 \%$ de los casos. Cursa con edema, eritema e isquemia que tiende a evolucionar a ulceración y necrosis profunda, pero localizada ${ }^{8}$; la biometría hemática muestra leucocitosis con neutrofilia. El loxoscelismo cutáneo-visceral es más grave; existe un componente sistémico asociado a coagulación intravascular diseminada, insuficiencia renal y daño hepático en las siguientes 24 horas $^{9}$, acompañado de anemia con reticulositosis, trombocitopenia, elevación de la bilirrubina indirecta, disminución de la haptoglobina ${ }^{10}$, hiperpotasemia, aumento de la creatinina, uremia, alteraciones de la coagulación y hemoglobinuria ${ }^{11}$.

\section{Caso clínico}

En nuestra institución se presentó un varón de 53 años, sin antecedentes de enfermedades sistémicas, que refirió el inicio de su padecimiento 4 días antes de su ingreso, con aumento de volumen, prurito y eritema del párpado superior izquierdo, y costras melicéricas

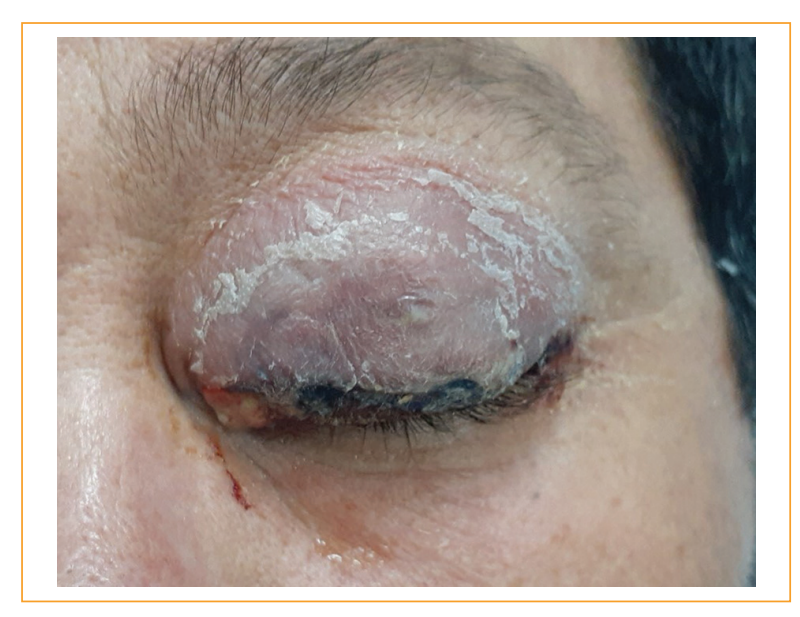

Figura 1. Celulitis del párpado superior izquierdo. Tercer día de hospitalización.

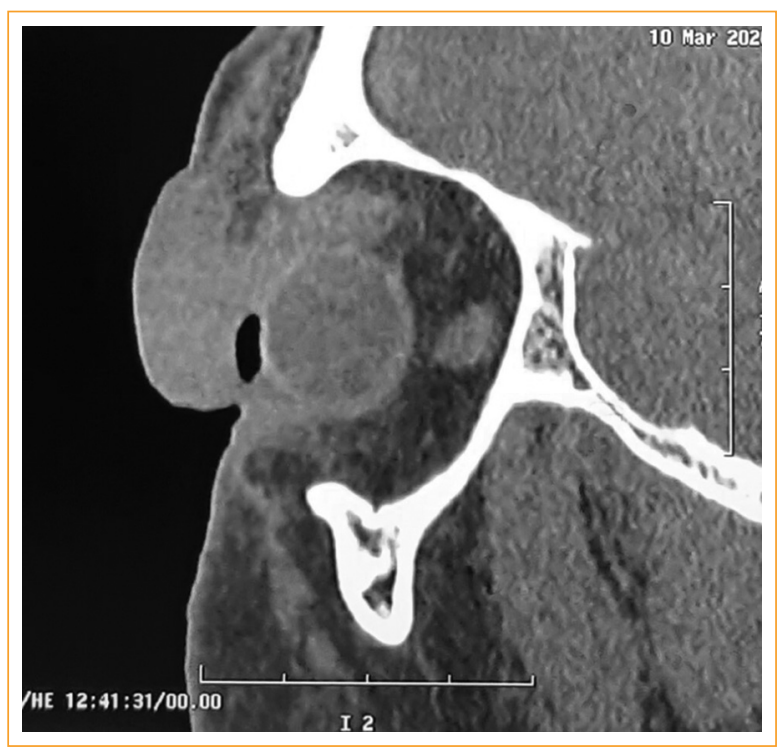

Figura 2. Tomografía computarizada sagital de órbita izquierda que muestra un contenido hiperdenso en la totalidad del párpado y el sector superior extraconal.

con aparentes lesiones punzantes pretarsales en el tercio medio (Fig. 1).

No era posible la apertura palpebral, por lo que solicitamos una tomografía computarizada que mostró material ocupativo hiperdenso en la totalidad del párpado, dirigido al sector superior extraconal de la órbita (Fig. 2). A su ingreso, infectología indicó ceftriaxona, vancomicina y dexametasona intravenosa. La 
biometría hemática mostró: hemoglobina $15.9 \mathrm{~g} / \mathrm{l}$, leucocitos $14.60 \times 10^{9} / /$ y neutrófilos $72.8 \times 10^{9} / \mathrm{l}$. Se realizó drenaje del absceso palpebral, con exploración y debridación de tejido necrótico preseptal (necrectomía), con curaciones diarias. El cultivo del material purulento no generó desarrollo. Desde el momento en que se logró la evaluación ocular, la agudeza visual y la función de los músculos extraoculares estaban preservados en la normalidad. En la evolución, el paciente desarrolló necrosis del tejido cutáneo en el tercio interno y medio de las zonas pretarsal y preseptal del párpado. Siete días después, en un segundo procedimiento quirúrgico, confirmando la ausencia de necrosis activa y de material purulento, se realizó necrectomía y refrescamiento de los bordes (Fig. 3) para la colocación de un injerto cutáneo de espesor completo que incluía fibras del orbicular, tomando como zona donadora el párpado superior contralateral mediante blefaroplastia. La evolución del paciente fue favorable, con integración del injerto cutáneo y sin complicaciones (Fig. 4).

\section{Discusión}

Debido a que es un problema de salud pública, consideramos de importancia presentar este caso. En México se mencionan entre 3000 y 5000 casos de mordeduras de arácnidos por año, y el $1.7 \%$ ocurren en la cara. Debido a la gravedad de los casos, debemos estar alertas e iniciar un tratamiento oportuno en conjunto con epidemiología e infectología. Los casos de loxoscelismo son los asociados al desarrollo de necrosis de tejidos provocada por vasculitis. La identificación del animal agresor se registra en menos del $5 \%$ de los casos, por lo que es recomendable tratar al paciente de forma intrahospitalaria para vigilancia y administración de antibióticos de amplio espectro y antinflamatorios intravenosos. El estudio inmunológico mediante ELISA (Enzyme-linked immunosorbent assay) detecta el veneno circulante, pero no se hace de forma sistemática, y el diagnóstico se basa en el cuadro clínico. En la literatura hay pocos casos descritos de aracnoidismo necrótico en el área palpebral; solo uno menciona haber realizado reconstrucción mediante un injerto cutáneo de espesor completo tomado de la región retroauricular en un paciente joven. En nuestro paciente, con un $40 \%$ de defecto de la superficie cutánea del párpado, determinamos realizar la reconstrucción con un injerto cutáneo de espesor completo tomado del párpado superior contralateral mediante blefaroplastia para un mejor resultado cosmético.

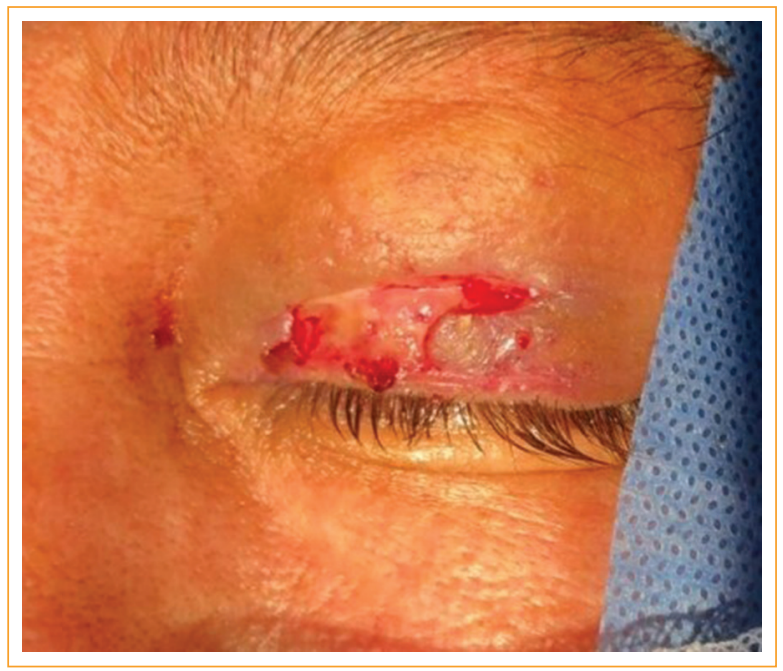

Figura 3. Necrectomía y refrescamiento de los bordes.

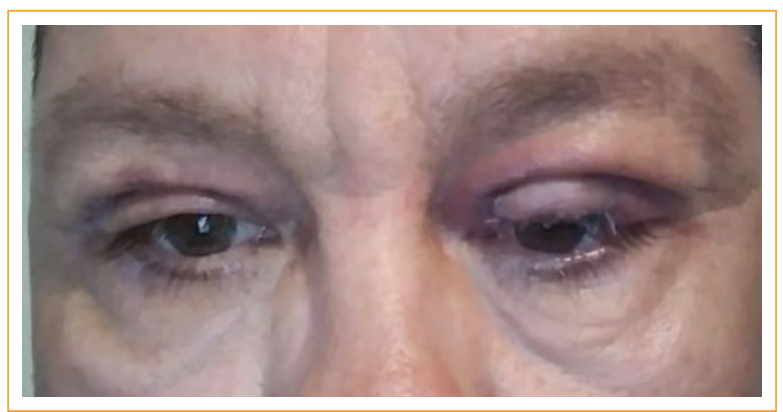

Figura 4. Aspecto a los 10 días de la toma y colocación de un autoinjerto cutáneo mediante blefaroplastia superior.

\section{Conclusión}

Es necesario tener en mente este tipo de padecimientos y descartar cuadros de diagnóstico diferencial, como infecciones por bacterias, ectima gangrenoso, infecciones virales (herpes simple o varicela-zóster), infecciones fúngicas, enfermedad venosa oclusiva (como vasculitis necrotizante), lesiones químicas, térmicas o traumáticas, e incluso el cuadro de StevensJohnson y la necrólisis epidérmica tóxica, para lo cual debe hacerse una anamnesis detallada.

Los cuadros de mordeduras por arañas venenosas pueden ser de gravedad variable, por lo que se debe mantener al paciente bajo vigilancia estrecha, alertando sobre el desarrollo de síntomas y signos sistémicos, y proceder de acuerdo a los protocolos establecidos. 


\section{Financiamiento}

Los autores no recibieron patrocinio para llevar a cabo este artículo.

\section{Conflicto de intereses}

Los autores declaran no tener ningún conflicto de intereses.

\section{Responsabilidades éticas}

Protección de personas y animales. Los autores declaran que para esta investigación no se han realizado experimentos en seres humanos ni en animales.

Confidencialidad de los datos. Los autores declaran que han seguido los protocolos de su centro de trabajo sobre la publicación de datos de pacientes.

Derecho a la privacidad y consentimiento informado. Los autores han obtenido el consentimiento informado de los pacientes y/o sujetos referidos en el artículo. Este documento obra en poder del autor de correspondencia.

\section{Bibliografía}

1. Consejo de Salubridad General. Guía de referencia rápida, diagnóstico y tratamiento de mordeduras por arañas venenosas. México. Reg.: SSA523- 11.

2. Zúñiga IR, Caro J. Aspectos clínicos y epidemiológicos de las mordeduras de araña en México. Hosp Med Clin Manag. 2018;11:191-203.

3. Ribuffo D, Serratore F, Famiglietti M, Greco M, Fois F, Atzori L, et al. Upper eyelid necrosis and reconstruction after spider bite: case report and review of the literature. Eur Rev Med Pharmacol Sci. 2012;16:414-7.

4. Bajin MS, Arikan G, Parlak M, Tuncok Y, Yigit N, Durak I, et al. Necrotic arachnidism of the eyelid due to Loxosceles rufescens spider bite. Cutan Ocul Toxicol. 2011;30:302-5.

5. Bilgili SG, Karadag AS, Karadag R, Cecen I, Calka O. A case of spider bite localized to the eyelid. Cutan Ocul Toxicol. 2013;32:83-5.

6. Jarvis RM, Neufeld MV, Twestfall C. Brown recluse spider bite to the eyelid. Ophthalmology. 2000;107:1492-6.

7. Cole HP, Wesley RE, King LE. Brown recluse spider envenomation of the eyelid: an animal model. Ophth Plast Reconstr Surg. 1995;11:153-64.

8. Keklikci U, Akdeniz S, Sakalar YB, Cakmak SS, Unlu K. Loxosceles reclusa bite to the eyelid. Eur J Ophthalmol. 2008;18:633-5.

9. Tay Zavala J, Díaz Sánchez JG, Sánchez Vega JT, Castillo Alarcón L, Ruiz Sánchez D, Calderón Romero L. Picaduras por alacranes y arañas ponzoñosas de México. Rev Fac Med UNAM. 2004;47:6-12.

10. Sistema Nacional de Vigilancia Epidemiológica. Boletín Epidemiológico. México. 2016;33:1-8

11. Sánchez Olivas MA, Valencia Zavala MP, Sánchez-Olivas JA, Sepúlveda-Velázquez G, Vega-Robledo G. Loxoscelismo cutáneo necrótico. Informe de un caso. Revista Alergia México. 2011;58:171-6. 